\title{
Testimonio de José María de Puelles y Centeno como médico durante la III Guerra Carlista
}

\section{Testimony of José María de Puelles y Centeno as physician during the III Carlist War}

\section{Testemunho de José María de Puelles y Centeno como um médico durante III Guerra Carlista}

\begin{abstract}
Molanes Pérez, Pablo*; Sáinz Otero, Ana M${ }^{a * *}$; Herrera Rodríguez, Francisco***
*Diplomado en Enfermería (Universidad de Cádiz). Alumno del Máster de Innovación e Investigación en Ciencias de la Salud y estudiante de $3^{\text {er }}$ curso de la Licenciatura de Historia.

${ }^{*}$ Enfermera. Antropóloga. Doctora en Medicina. Profesora de Bases Teóricas y Metodológicas de los Cuidados de Enfermería en la Facultad de Enfermería y Fisioterapia de la Universidad de Cádiz.
\end{abstract}

${ }^{* * *}$ Catedrático de Historia de Enfermería en la Facultad de Enfermería y Fisioterapia de la Universidad de Cádiz

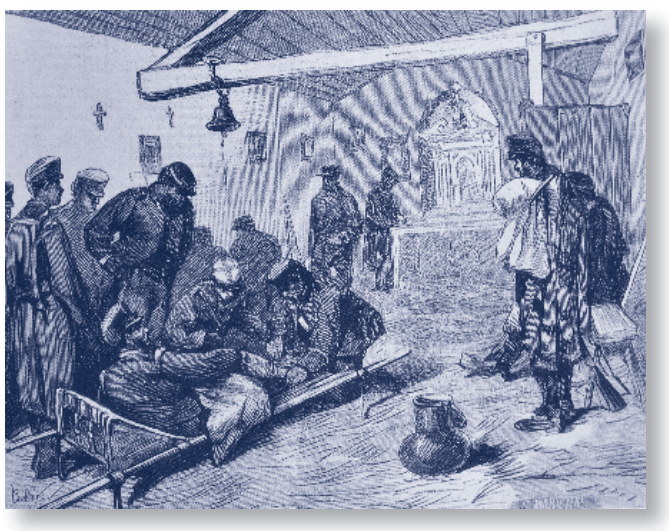

Imagen 1

Testimony of José María de Puelles y Centeno as physician during the III Carlist War

\section{ABSTRACT}

The memoirs of Jose Maria de Puelles y Centeno, allows us to analyze, on the medical condition of the sanitary situations of the sick and wounded between 1873-1876, during the Third Carlist War in the different fronts in which it participates and the role played by the Sisters of Charity and the International Red Cross in care of the soldiers. Comparison with other primary sources of the time allows us to compare the information you give about the development of the war.

Keywords: Sisters of Charity, Carlist War III, MD, José María de Puelles and Centeno, International Red Cross, Healthcare.

Testemunho de José María de Puelles y Centeno como um médico durante III Guerra Carlista

\section{RESUMO}

As memórias de José Maria de Puelles Centeno e permite-nos analisar, com a condição médica das condições sanitárias dos enfermos e feridos entre 1873-1876, durante a Terceira Guerra Carlista nas diferentes frentes em que participa e o papel desempenhado pelas Irmãs da Caridade e da Cruz Vermelha Internacional no cuidado dos soldados. Comparação com outras fontes primárias do tempo nos permite comparar as informações que você dá sobre o desenvolvimento da guerra.

Palavras-chave: Irmãs da Caridade, carlistas War III, MD, José María de Puelles e Centeno, Cruz Vermelha Internacional, Healthcare. 


\section{RESUMEN}

Las memorias de José María de Puelles y Centeno nos permite analizar, por su condición de médico las condiciones sanitarias de heridos y enfermos entre 1873-1876, en el transcurso de la III Guerra Carlista en los diferentes frentes en los que participa, así como el papel que jugaron las Hermanas de la Caridad y la Cruz Roja Internacional en los cuidados de los soldados. La comparación con otras fuentes primarias de la época nos permite contrastar la información que nos da sobre el desarrollo del conflicto bélico.

Palabras clave: Hermanas de la Caridad, III Guerra Carlista, Médico, José María de Puelles y Centeno, Cruz Roja Internacional, Asistencia sanitaria.

Este artículo es la ampliación de uno de los puntos de la comunicación "Apunte biográfico sobre el médico José María de Puelles y Centeno (1853-1927)" presentada al XV Congreso de la Sociedad Española de Historia de la Medicina, celebrado en Ciudad Real del 15 al 17 de junio del 2011.

\section{INTRODUCCIÓN}

Los relatos autobiográficos nos proporcionan una fuente primaria de información que nos permite contrastar y construir de forma mas fidedigna la historia, sobre todo a partir del desarrollo de la corriente historiográfica defensora de la microhistoria como la principal fuente histórica. El testimonio autobiográfico que nos proporciona José María de Puelles y Centeno a través de sus memorias nos permite, por su condición de médico del ejército liberal y prisionero del ejército carlista analizar no solo el desarrollo de la III Guerra Carlista, sino también analizar el estado sanitario de ambos bandos, de un valor excepcional. Tanto su persona como su obra han sido escasamen- te estudiadas por los investigadores, haciendo una escueta referencia Antonio Orozco Acuaviva en "Médicos escritores gaditanos" (1978). Su vida ha llegado a nuestros días a través de sus obras, "Recuerdos de mi juventud" (1907) y "Como le quieran llamar. Colección de artículos, discursos y consejos" (1908).

\section{INFANCIA Y FORMACIÓN}

José María de Puelles y Centeno nace el 27 de Febrero de 1853, en la ciudad de Alcalá de los Gazules (Cádiz) ${ }^{1}$. Su infancia la vive en su ciudad, rodeado de su familia, grandes propietarios de tierras y con un activo papel en la política local y provincial.

Cursó los estudios de Medicina en Cádiz entre 1869 y 1873 , en pleno "sexenio revolucionario", con unas calificaciones mediocres, tal y como justifica en su autobiografía "no con el aprovechamiento que debiera pues la política, el profesorado -pues yo explicaba Geografía, Historia y Retórica en el Colegio de San Carlos Borromeo- y la novia, que luego fue mi mujer, me distraían no poco el estudio". Logra finalizar la carrera, revalidando los estudios en la Facultad de Medicina el 28 de Marzo de 1873.

En abril de 1873 recibe su primer trabajo, como médico titular de Jimena de la Frontera. Fue llamado a Servicio Militar Obligatorio para incorporarse al ejército liberal en la III Guerra Carlista ${ }^{2}$. Entre el 17 y el 19 de noviembre recibió la orden de incorporarse a la Brigada Sanitaria de Madrid. A los pocos días de su llegada a Madrid es nombrado médico del Batallón de Cazadores de Segorbe No 19 y parte para Bilbao.

\section{TESTIMONIO DEL CONFLICTO BÉ- LICO}

La principal fuente de información sobre su participación en la guerra la tenemos a partir de sus memorias, las cuales tienen como eje 
central sus vivencias en el frente ${ }^{3}$. La partida de Cádiz a finales de noviembre de 1873 la describe de la siguiente forma:

"Y no hubo otro remedio que abandonar, tal vez para siempre, aquel hogar querido donde dejaba todos mis amores -mis padres, mi mujer, mis hermanos- para lanzarme a lo desconocido, a la lucha terrible entre los hijos de la pobre España, que en fratricida guerra estaba consumiendo la flor de la juventud."

De las condiciones higiénicas de los heridos nos dirá respecto al Hospital de Portugalete que "más parecían calabozos, en los cuales, si bien no se corría el peligro de morir por armas de fuego, en cambio, dada su humedad y escasa luz y ventilación, era muy posible la infección, como así, por desgracia, me sucedió a mí." Por la ubicación del hospital que $\mathrm{da}$, "situado entre el muelle y la suntuosa Parroquia", se trataba del hospital instalado el 1 de noviembre de 1873 en la casa de Benigno Salazar, por reunir mejores condiciones de defensa frente a un posible ataque, según refiere el Teniente Coronel D. Amós Quijada ${ }^{4-5}$.

En las inmediaciones del campo de batalla solía acondicionarse también Hospitales de Sangre, normalmente en iglesias y grandes casas (ver imagen 1). Nuestro biografiado nos ofrece el cuadro de la situación del Hospital de Sangre instalado en la Iglesia de Villafranca del Cid, tras la batalla del Barranco de Molleó del 29 de junio de 1875.

"Era horrible el aspecto de aquel santo lugar. Todas las capillas y las tres naves estaban macizadas de camas, en cuyos lechos se revolcaban horriblemente mutilados y desangrándose soldados y oficiales. En los altares chisporroteaban los cirios que alumbraban aquel cuadro de ho- rror: aquí se hacía una amputación, allá se oleaba a un agonizante, acullá gritaba en el delirio de la fiebre un soldado llamando a su madre, y por todas partes camilleros, sanitarios con vendajes, médicos con cuchillos y bisturís, y entre el toque de las campanas de las Animas, el trotar de los caballos que pasaban por la cercana calle, el eco de las cometas y clarines, los ayes de los moribundos y los ruidos de las espuelas y de las armas aquello parecía una escena propia para ser descrita por la incomparable pluma del divino Dante".

No será el único testimonio de la situación sanitaria en el bando liberal. Podemos destacar el testimonio de Vicente Kennett-Barrington, que participó como colaborador de la Orden Hospitalaria de los Caballeros de San Juan de Jerusalén en tres expediciones (abrilmayo 1874; octubre 1874-mayo 1875; septiembre 1875-mayo 1876) y de Concepción Arenal, como enfermera del hospital de la Cruz Roja en Miranda del Ebro.

De la asistencia sanitaria en el bando carlista nos ofrece nuestro médico el testimonio de su paso como prisionero enfermo por el Hospital de Santurce, al que califica de "un amplio y vetusto palacio". Vicente KennettBarrington visitó los hospitales de Santurce el 3 de mayo de 1874, dos meses después de la liberación de nuestro biografiado; apuntando en su diario que "Nunca había visto nada tan magnificamente organizado como los hospitales de Santurce”. Según las anotaciones que recoge, los cuatro hospitales de Santurce tendrían una capacidad de 350 camas, siendo el de " $L a$ Fonda" el mayor ${ }^{6}$.

IV. LAS HERMANAS DE LA CARIDAD Y LA CRUZ ROJA EN LA CONTIENDA

José María de Puelles se hace eco de la 


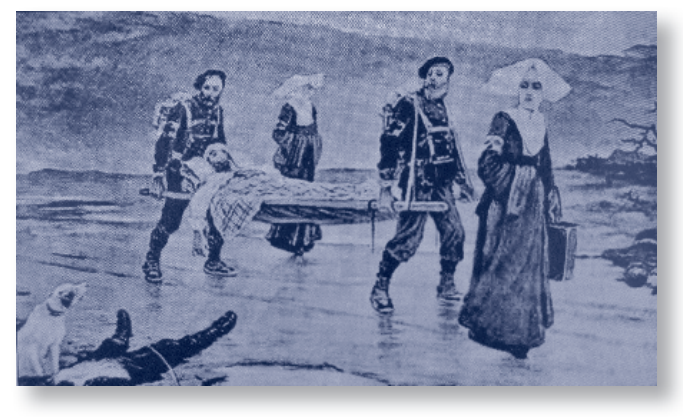

Imagen 2

atención sanitaria y del papel de los cuidados de las Hermanas de la Caridad durante su hospitalización en Santurce ${ }^{7}$. Se recuperó según él por "el bienhechor oxígeno de aquel salón amplio, la paz y reposo relativos de mi espíritu, la buena alimentación, los exquisitos cuidados de las hermanas de la Caridad". La Asociación de las Hermanas de la Caridad venía a realizar las mismas funciones en el ejército carlista que la Cruz Roja Internacional, ya que pese a atender heridos de ambos bandos, la Cruz Roja no pudo actuar en la zona carlista, por no ser considerada por las potencias europeas como beligerante el dominio de Carlos VII (ver imagen 2). El doctor Nicasio Landa refiere la igualdad en el trato a heridos de ambos bandos en la carta que dirigió a la duquesa de Medinaceli el 9 de julio de 1874: "Muchas veces contemplé conmovido el hermoso cuadro que representaba un herido liberal llevado en brazos de dos fornidos soldados

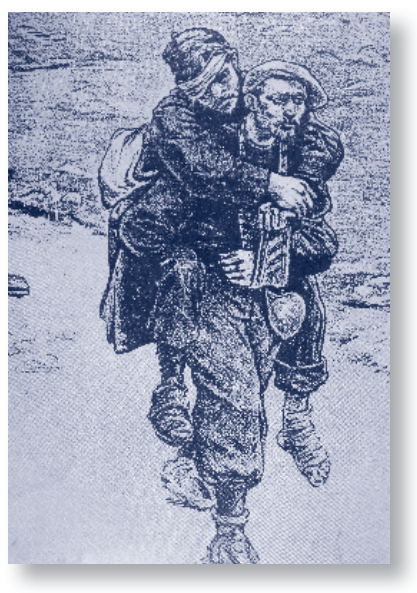

Imagen 3 eran insuficientemente curados y socorridos. Aún recordamos haberlos visto hacinados en habitaciones pequeñas, insalubres, en el hospital que se había improvisado en Abárzuza. El médico no tenía residencia fija en el hospital; y las camas y demás efectos eran debidos al desprendimiento particular de los vecinos de los pueblos comarcanos. El irremplazable instituto de las Hermanas de San Vicente de Paúl era sustituido por sus propias madres. Uno de los espectáculos que más presente se nos quedó en el recuerdo fue el ver a dos heridos carlistas, padre e hijo, asistidos varonil, pero nada facultativamente, por la esposa y madre de ambos desgraciados."

\section{PROTECCIÓN DE LOS ENFERMOS Y HERIDOS}

La actuación a lo largo de la guerra de la Cruz Roja Internacional y las Hermanas de la Caridad marcarían un precedente en España, en cuanto al derecho humanitario sobre la atención a los caídos en campo contrario. Tenemos ejemplo a partir del oficio del 1 de marzo de 1873, por el cual el coronel del Regimiento de Lusitania disponía que: "La persona de todo carlista que se encuentre herido en los pueblos se considerará sagrada. Todo carlista que se coja herido después de un combate quedará indultado". Nicasio Landa, médico militar e inspector general de la Cruz Roja Española atestigua, como le carlistas. ¡Qué inmensidad de consideraciones se presta!" (ver imagen 3). El primer año de la contienda el papel de las hermanas de la Caridad era llevado a cabo por familiares y voluntarios $^{8}$, como recoge el general de artillería carlista Antonio Brea:

"El vacío era grandísimo; los pobres heridos sucedió a José María de Puelles y Centeno, que
los Hospitales de las hermanas de la Caridad acogieron en Logroño a heridos liberales.

De esta forma los hospitales se convierten en sitio de refugio de la población, como ocurrirá durante el cañoneo de la ciudad de Santurce por las tropas liberales "se llenó el 
Hospital de mujeres y niños de todas las clases sociales, sin duda alguna porque suponían con razón que sobre él no dispararían, en atención a ondear sobre su torre la santa enseña de la Cruz Roja."

Sin embargo esta inmunidad no podrá ser garantizada siempre, ya que durante el sitio de Portugalete, pese a estar protegido por la Convención de Ginebra de $1864^{9}$ y enarbolar la bandera de la Cruz Roja el edificio del hospital sufrió los impactos de proyectiles, debiendo trasladar a los heridos graves a los sótanos para protegerlos.

Las partes enfrentadas debieron pactar treguas temporales para recoger los cadáveres y darles entierro; como refiere Puelles, el cerco de los carlistas a Portugalete provocó que "los cadáveres permanecían insepultos tres y cuatro días" y la acumulación de enfermos y heridos daba al "Hospital un hedor insoportable y un peligro horrible".

Fundamentándose en el Convenio Eliot se dispuso el intercambio general de prisione$\operatorname{ros}^{10}$. De la misma forma, en Cataluña, Martínez Campos y Tristany firmaron un convenio el 27 de febrero de 1875, por el cual se permitía el paso libre de soldados heridos. José María de Puelles refiere el hecho atroz ocurrido en Cataluña "tuvo la inhumanidad de sacar de un hospital de los suyos a un médico provisional nuestro y fusilarlo sin tener en cuenta que no era un voluntario, que le amparaba y protegía la Convención de Ginebra y que estaba curando $y$ asistiendo a los heridos de su propio campo." 1 También nos refiere José María de Puelles que él mismo contravino el Convenio de Ginebra, al encomendarle el Capitán General, Sr. Burgos, trasladar al brigadier del Batallón Iriarte un pliego con instrucciones de comunicación entre las autoridades militares.

José María de Puelles, siguiendo estos principios humanitarios no duda en asistir a los enfermos del hospital de Santurce cuando el médico carlista se hallaba ausente. De la misma forma en Iglesuela del Cid debe hacerse cargo de los heridos del hospital de sangre carlista, al carecer este de médico. La falta de personal sanitario es una tónica común en ambos ejércitos, debiendo nuestro biografiado cambiar varias veces de Batallón durante la contienda ante a la ausencia de médicos. Recibió ofertas de Urbina, secretario del estado mayor, durante su convalecencia en Santurce, para que se pasara a la causa carlista, según refiere "por la escasez de facultativos en el campo carlista".

\section{CONDICIONES DE TRABAJO E INNO- VACIONES SANITARIAS}

Las duras condiciones de trabajo de los sanitarios de ambos bandos durante la guerra se manifiestan en la "fiebre gástrica" que contrae nuestro médico en el mes de enero de 1874 en Portugalete, "por exceso de trabajo y mala alimentación", así como la anemia severa que le impide prestar servicio en campaña provisionalmente durante su estancia en Zaragoza. Su labor médica en el campo de batalla no estaba exenta de peligro, como demuestra en la batalla del Barranco de Monlleó, el 29 de junio de 1875: "Subí mientras pude en mi caballo aquella agria y escabrosa montaña oyendo los silbidos de las balas a derecha e izquierda, $y$ así que estuve en la meseta del cerro empecé a curar heridos que retiraban los camilleros." También dejará testimonio de las duras jornadas de trabajo a las que se enfrentaban los sanitarios, como relata de la noche siguiente a la batalla de Monlleó diciendo que esa noche no se retiraron los médicos hasta las dos de la madrugada, quedando José María de Puelles de guardia, sin poder conciliar el sueño en toda la noche "ya le sobrevenía a un herido un síncope, ya una hemorragia, ya a otro se le aflojaba un vendaje o se lo arrancaba en su delirio." 
Pero no solo escaseará el personal sanitario en ambos bandos, sino también material médico, dándose el caso que según el testimonio de Puelles el día 21 de enero de 1874, fecha de la rendición de la ciudad de Portugalete a las tropas carlistas: "A eso de las once o doce del día se me presentaron tres médicos carlistas vestidos de uniforme, que no venían, como tuvieron buen cuidado en decírmelo, a celebrar consulta por el compañero enfermo, sino a que les entregara el material sanitario que hubiese en mi poder. Yo le encargué a mi asistente les diera la caja de operaciones y se marcharon sin más ni más.”

Pese a todo ello durante la guerra carlista se introducirán importantes novedades en la atención sanitaria a los heridos y enfermos, como la dotación a los sanitarios con mochilas botiquines de campaña o la creación por los Carlistas del servicio de Ambulancias Volantes $^{12}$ (ver imagen 4). Gimenez Enrich, reportero de guerra liberal dirá de estos carros: "En la plaza de Lacunza estaban expuestos a nuestra vista los magnificos carruajes de ambulancia, para transportar ocho heridos acostados y cuatro sentados, de que se servía la benéfica Asociación de La Caridad. A los ojos de muchos, este sistema, basado en los últimos progresos de la Sanidad Militar, y oficialmente adoptado por todas las naciones civilizadas, excepto por las nuestra, constituía una novedad insigne." En los hospitales carlistas como el de Irache contaban con los más modernos equipos, incluyendo aparatos ortopédicos, colchones de goma elástica y cajas de instrumental quirúrgico modernas, importados del extranjero.

\section{FIN DE LA CONTIENDA Y REINCOR- PORACIÓN A LA VIDA CIVIL}

La guerra terminó con la entrada del General Primo de Rivera en Estella el 19 de febrero

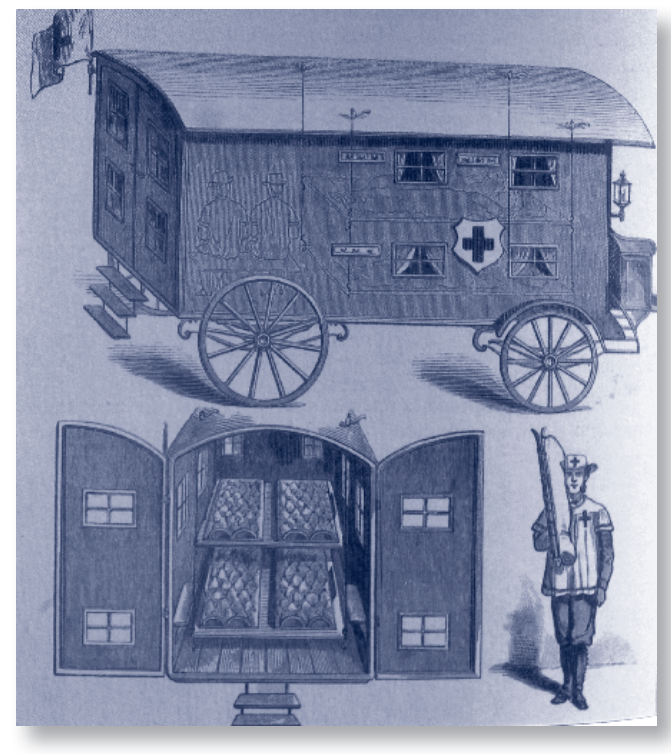

Imagen 4

de 1876, cruzando el pretendiente la frontera francesa por Valcarlos el día 27 de febrero. José María de Puelles es licenciado en mayo de 1876 regresando a Alcalá de los Gazules como médico titular. Entre 1883-1889 cursará la carrera de Derecho, abandonando definitivamente el ejercicio de la medicina en 1901, cuando obtiene la notaría de Medina Sidonia. Fallece el 8 de enero de 1927 en Medina Sidonia, a los 73 años ${ }^{13}$.

\section{CONCLUSIONES}

La importancia de la figura de este médico alcalaíno radica en el valor del testimonio que nos lega a partir de sus escritos, que sin duda ayuda a esclarecer y comprender mejor unos años convulsos de la historia política y sanitaria de España. En palabras suyas: “TTriste destino el mío, haber sido súbdito de todos los gobiernos posibles en tan poco tiempo, desde la anarquía hasta el poder absoluto, desde el cantón federal en Jimena hasta la monarquía tradicional en Santurce!". 


\section{NOTAS}

1- Archivo Parroquial Iglesia de San Jorge (Alcalá de los Gazules). Libro de Bautismos nº 1 . Folio 641.

2- Algunos historiadores consideran que se trata de la segunda, ya que no consideran como tal la Insurrección de Cataluña, también llamada Guerra de los Matiners (1846-1849). (Garmendia, Antoñana, Asín, 2007)

3- La Guerra comenzó el 14 de abril de 1872, cuando D. Carlos instigó el pronunciamiento desde su refugio en Ginebra. Un conglomerado de fuerzas tradicionalistas, cuyos principales fines eran la restitución de los fueros, la unidad católica del país y la oposición al sistema liberal-capitalista. Como consecuencia del periodo convulso de la Revolución de la Gloriosa (1968), de la I República y del Reinado de Amadeo de Saboya habían conseguido atraer a una parte desencantada de los partidarios Isabelinos hacia la causa carlista (Antoñana, 1990).

4- Archivo Histórico Municipal de Portugalete. Libro de Actas fecha 30.10.73.

5- El 21 de marzo de 1874 se habilitó como hospital las casas del Muelle Nuevo, con una capacidad según las observaciones de Kennett-Barrington para 200 camas.

6- Seguramente sería en el que fue hospitalizado José María de Puelles y Centeno. Según Kennett-Barrington el 3 de mayo de 1874 acogía un total de 117 ingresados (4 heridos carlistas; 1 herido liberal; 109 enfermos carlistas; 3 enfermos liberales).

7- La Caridad es creada en noviembre de 1873, promovida por Margarita de Borbón, esposa de Carlos VII.

8- La organización de la sanidad militar en el ejército carlista no se desarrolla hasta bien entrado el conflicto.

9- La Primera Convención de Ginebra de 1864 titulada "Convenio de Ginebra para el mejoramiento de la suerte que corren los militares heridos en los ejércitos en campaña de 1864" fue impulsada por Jean Henri Dunant, fundador de la Cruz Roja.

10- El Convenio de Eliot fue firmado el 27 de abril de 1835, durante la I Guerra Carlista, por la mediación de Lord Edward Eliot (1798-1877), Comisario Británico. Sirvió para reducir los fusilamientos indiscriminados de heridos y presos de ambos bandos.

11- Refiere ser responsabilidad este hecho del Capitán General del Ejercito Real de Cataluña, Francisco Savalls y de Massot, que ocupó la jefatura del Ejército de Cataluña entre marzo y septiembre de 1875 . Este hecho contravenía lo pactado en la Convención de Ginebra por la cual el personal sanitario era considerado neutral y debía atender a heridos y enfermos de ambos frentes amparándose en los principios de humanidad.

12- Carros de caballos dotados con cajas de curas e instrumental para atender a los heridos insitu en el campo de batalla y hacer el trasporte de forma confortable.

13- Registro Civil de Medina Sidonia. Libro de Defunciones. Tomo 64. Página 203.

\section{BIBLIOGRAFÍA}

- Caspistegui,F.; Larraz,P.; Ansorena,J. (2007). Aventuras de un gentleman en la tercera carlistada. Imágenes de la sanidad en guerra, 1872-1876. Gobierno de Navarra, (Pamplona)

- De Puelles,J.M. (1911). Recuerdos de mi juventud. Imprenta Manuel Álvarez Rodríguez, (Cádiz)

- Orozco,A. (1978). Médicos Escritores Gaditanos. Colegio Oficial de Médicos, (Cádiz)

- Garmendia, V. (1976). La Segunda Guerra Carlista (1872-1876). Siglo XXI Editores, (Madrid)

- Clemente, J.C. (1982). Las Guerras Carlistas. Ediciones península, (Barcelona), 236-237

- Viñes, J.J. (2001). El doctor Nicasio Landa. Médico y escritor. Pamplona 1830-1891. Gobierno de Navarra, (Pamplona).

- Larraz,P. (2005). La sanidad militar en el ejército carlista del norte (1833-1876). Aportes: Revista de Historia Contemporánea, 58, 37-49.

- Brea,A. (1897). Campaña del Norte de 1873 a 1876. Imprenta de la Hormiga de Oro, (Barcelona), 24-25.

- Parés,M.E. (1977). La sanidad en el partido carlista (primera y terceras guerras carlistas). Medicina e Historia 68, 8-26.

- Arenal,C. (2005). Cuadros de la Guerra Carlista. Facsímil de la primera edición de 1880. Renacimiento, (Sevilla)

- Villaluenga,J. (2007). La sanidad y la beneficencia de Portugalete a mediados del siglo XIX. Sancho el Sabio 26, 11-23

- Puelles, J. Genealogía de los Puelles. Disponible en: http://www.jpuelleslopez.com/GenPuellesC.htm\#genc [consultado 12-04-11] 